\title{
The tort and legislative regulation of standard terms in shopping online between undergraduates
}

\author{
Li Zhao, Wenxing Zhen and Xiaodong Liu \\ School of North Chnia Electrict Power University, Baoding, 071000, China
}

Keywords:college student consumer group, online shopping, standard terms tort, Legislative regulation

\begin{abstract}
With the network economy, logistics services and mobile applications have developed rapidly in twenty-first century,online shopping has become one of the most popular ways for Chinese consumers.But the online shopping has strong virtuality and are not perfect in legal regulation,so it's common to see the standard terms tort disputes in online shopping.College students become the main victims of online shoppong standard terms tort disputes because they have weak economic strength,lack of experience and adequate legal knowledge. A study on the tort of standard terms in online shopping and take college students as representatives will help us discuss the legal regulation of standard terms tort problems and help us protect consumers' right better.
\end{abstract}

\section{Problem-posing}

"Internet plus" as a new economic model has stimulate consumption demand and give the China's economy,"fission".Online shopping as the representative of e-commerce has penetrated into all aspects of daily life.In the enjoyment of online shopping as well as express delivery of the fast, while the legal issues hidden in the online shopping can not be ignored, especially the standard terms tort problems.

Online shopping is very common among College Students and they has the representative of consumers.the purchase of goods range of college students is very broad, the choice of online shopping platform also has a variety of trends.The characteristics of college students with high quality, high education background and the lack of legal consciousness are in sharp contrast.Specific performance in college students is that lacking of social experience,attaching much weight to price instead of quality, blinding self-confidence and lacking of mental capacity.The group is the weakest link in the consumer.Therefore, regard the college students as a breakthrough point in the study of online shopping standard terms tort problems present situation investigation and Legislative regulation is easier to analyze the problem comprehensively and thoroughly and protect consumer's right.

\section{The concrete embodiment of the standard terms tort in the online shopping.}

\subsection{The tort in the user agreement.}

User agreement refers to the agreement between the consumer and the shopping platform when the consumer using the online shopping platform to purchase goods.It is a typical standard terms developed by the shopping platform unilaterally without negotiable.First, the form of it has problems. The form of making a user agreement in Online shopping is not standardized.Standard terms are generally used as a clickwrap attached to the consumer's account application page, as to it's specific content requires consumers to click on the word to jump link reading.Next, the consumer will only register a member account once a time, but the content of the user agreement will improve and constantly change with the development of shopping platform,law progress and other factors.Consumers do not have a reasonable opportunity to read the standard terms. And the network operators have not been able to fulfil their reasonable notice obligation especially on the modified terms.Secondly, the content of the user agreement has problems.User agreement as a 
standard terms developed by shopping platform unilaterally, most of the terms will be conducive to the shopping platform, increase the consumer's responsibility or limit and exemption from their own responsibilities.For example,Dangdang.com in the user agreement said:"The website send a e-mail to the consumer to confirm receipt of the order does not constitute a commitment, only when it issued to consumers shipping confirmation email to inform consumers of products have been issued, then it established the contract for pledge."Some consumers pay for the order but can not get the operator's commitment, which is the embodiment of inequality between the two sides of the contract.

\subsection{Analysis of typical standard terms tort in C2C model.}

In the $\mathrm{C} 2 \mathrm{C}$ electronic business model, the standard embodied in the home page of the respective shops or merchandise page.These standard terms are multifarious and disorderly,has different characteristics.The following we will selection two kinds of typical standards terms to analysis.

2.2.1 If the product don't have quality problems, but different from customers' imagine we will not support to returned.

First, the buyer's imagination and perception of the goods from the merchant introduction, businesses should as much as possible to restore the real goods in their introduce. In other words, businesses have a certain responsibility for consumer imagination.Second,this kind of clauses obviously transgress the regulation that consumers can return the goods that remove some specials without any reason in seven days in 《Consumer Protection Law》.At the same time,this kind of clauses also eliminate and restrict the right of consumers.As a result,consumers will suffer from unfair treatments.

\subsubsection{Reject the bad review.If you will give us a bad review,please don't buy our goods.}

Evaluating the purchase of goods is consumers' rights.We know that evaluating the purchase of goods is one of methods that is used to maintain legal rights.But,the proprietor reject the bad reviews in real life.This kind of practice not only limit consumers' right to some extent,but also keep out the right that consumers can critic goods and use this method to contact their rights. This kind of clause is named as "arbitrary clause" should not have legally enforce.

\subsubsection{The standard terms in The express transport.}

The development of logistics industry is closely linked to the development of electronic commerce.But in our country,express delivery still have problems because of the standard terms such as limit of indemnity.Courier contracts generally attached at the back of the delivery sheet, sending its content to express value and valuation of the amount limit.If this express item that don't get insured go wrong,amount of limitation is not more than three times as much as express fee.Courier contracts is in common use in express delivery.So,treaty contents whatever limitation of liability or insured clause are alike whit minor difference.Therefore,consumer must accept the standard terms in The express transport if they want to post express items.

\section{The main obstacle to college students online shopping rights.}

\subsection{College students are lack of legal knowledge.}

According to the survey,only four point three two percent of students have a little comprehensive understanding of the standard terms.College students can not clearly identify this is the sign of Format Contracts Infringement,not to mention discriminate format contracts that claimed by the proprietor have or not have legally enforce.Thy also don't know What are the way to maintain legal rights, what evidence need to retain and which subject can we believe rights.Therefore ,even if we want to maintain our legal rights,but we don't have any ways.

\subsection{The high cost to Maintain the rights.}

College students Prefer to buy low-priced products because them Limited spending power.If products have problems,even if proprietor agree to return products,college students need to home freight.There's no meaning to return products when the freight is almost the half of commodity prices or over commodity prices.If college students select to maintain legal rights by legal approach,the high cost such as expense in litigation 、 attorney fee and Long case judgment 
time bring heavy economic burden and time burden to students.College students don't have enough economic strength and time cost to choose legal way to solve the problem of format terms infringement in the network shopping.

\section{The legal regulation}

\subsection{The legislative regulation}

\subsubsection{Explain the effectiveness of the standard terms in detail.}

The specific content and the way to enter into a contract have an impact on the effectiveness of the standard terms,so, the standard terms is not necessarily effective.The effectiveness of the clause in network shopping is different from the effectiveness of the clause used by traditional trading terms.Lawmakers need to make more detailed legal interpretation to determine the effectiveness of the network format terms because The current law of our country that stipulate usual contract invalid situations and format terms invalid situations can not resolve Network infringement of format terms.

\subsubsection{Increase the intensity of punishment if standard term provider breach of duty.}

Our country's law only have terms to stipulate how to use standard term v the effectiveness of standard term、Standard term provider's hint, explanation obligation, but don't have terms to the intensity if standard term provider breach of duty.Penalties is not easy to cause the network operators illegal costs less than law-abiding cost, through the abuse of format terms limit or be exempted from liability, encroach on consumer rights, to achieve the purpose of to obtain illegal interests. Therefore, we need to increase the intensity of punishment if standard term provider breach of duty by drawing up Specific legal norms.

\subsection{The judicial regulation}

The standard terms in the online shopping generally take the form of electronic data. However in most of the shopping platform for user agreement, shopping platform shall have the right to login user accounts to obtain evidence in a dispute. Network operators in the use of electronic data has technical advantages, can be used as evidence of the electronic data is easy to be changed by network operators. Therefore, the civil procedure proof of principle "who advocate who proof" is not good for consumers to maintain their own rights. In the case of infringement of the online shopping format terms, the proof of principle which is benefit for consumers should be established,and realization the substantial equality on the litigation rights.

\subsection{The administrative rules and regulations}

In order to prevent the standard terms encroach on consumer rights, and guarantee the standard terms providers make a fair and reasonable standard terms, administrative departments should consider both prior review and post supervision and inspection.Prior review, The administrative department can build review records system for the standard terms, the provider of the clause will be submitted to the administrative department of the proposed standard terms to review, and for the record. After can be built into the contract of online shopping. Due to the most of the operators in C2C and B2C online shopping platforms ,administration department in the online shopping service platform format contract to a third party audit for the record the draft copy of the format contract at the same time, or to illustrate the matters shall be recorded and should not be in the standard terms. In order to standardize behavior of the many online self-employed to make standard terms. Post-supervision, administrative departments should not only supervision each big shopping platform proposed format clauses by theirselves, but also investigation the customer complaints in time.

\section{Conclusions}

Online shopping standard terms, which affects not only college students also affect the network shopping industry's rapid development. About the infringement problem of the standard terms in online shopping,should from two aspects of subjective and objective to resolve.In Objective,we should to strengthen the legislative, judicial and administrative regulations, and three kinds of 
measures to mutual collaborate, benign interaction, and form a effective mechanism which can strict specificate the standard terms of in the network shopping.But it should be achieved the balance between the standard terms regulation and maintain business economic development, don't overdo and affect the normal development of the network shopping economy.

\section{References}

[1] Jingjing Xu. Discuss the network shopping standard terms [J]. Journal of society and law, 2012, 4.

[2] Wen Su.Seven typical network transaction unfair standard clauses review [J]. China business news, 2015, 9.

[3] Xiaoxiao Li .Na Li. Feng Gao. Present situation of college students' online shopping and countermeasure analysis [J] China trade, 2011.

[4] Jingyi Shi. The rights of college students' online shopping and mess - Ephraim economics analysis perspective [J]. The rule of law, 2015.

[5] Zhedong Yong. In the electronic commerce consumer rights and interests safeguard mechanism is analysed. Based on the present situation of college students' online empirical research [J]. Journal of electronic commerce, 2014.

[6] Yue Li. B2C online shopping contract legal issues research [D]. Fudan university, 2013.

[7] Hanying Du. About shopping web site user agreement validity of format terms of research [D]. Tianjin normal university, 2014.

[8] Liuliu Yang. W.k.che network shopping contract issues [D]. Fudan university, 2013.

[9] Jianou Jiang. Theory of online shopping format terms [D]. Nanjing normal university, 2011.

[10] YongCheng Ju. Case analysis of the C2C online shopping security [D]. Lanzhou university, 2010. 